\title{
ALT Levels in Treatment-Naive, Chronic Hepatitis B Patients with Concurrent Fatty Liver Disease: A US Nationwide Study
}

\author{
Christine Y. Chang ${ }^{a, b}$ Leslie Kam ${ }^{a} \quad$ Nolan Dang ${ }^{a} \quad$ Ramsey Cheung ${ }^{a, c}$ \\ Mindie H. Nguyen ${ }^{a, d}$
}

${ }^{a}$ Department of Medicine, Gastroenterology and Hepatology, Stanford University Medical Center, Palo Alto, CA, USA; ${ }^{b}$ Department of Medicine, California Pacific Medical Center, San Francisco, CA, USA; 'Department of Medicine, Gastroenterology and Hepatology, Palo Alto Veterans Administration Medical Center, Palo Alto, CA, USA; ${ }^{\mathrm{d}}$ Department of Epidemiology and Population Health, Stanford University Medical Center, Palo Alto, CA, USA

\section{Keywords}

Chronic hepatitis B · Hepatitis B virus · Nonalcoholic fatty liver disease $\cdot$ ALT elevation

\begin{abstract}
Introduction: Treatment criteria for chronic hepatitis $\mathrm{B}(\mathrm{CHB})$ relies on ALT, which can be impacted by concurrent nonalcoholic fatty liver disease (NAFLD), but ALT data on patients with CHB and NAFLD are limited. We aimed to characterize ALT distribution in untreated CHB patients with NAFLD. Methods: We retrospectively analyzed untreated US adults with CHB (533 with NAFLD, 3,172 without NAFLD) using the Clinformatics $^{\text {tw }}$ Data Mart Database (2003-2019). The main outcome was ALT elevation ( $>1 \times$ upper limit of normal, $35 / 25 \mathrm{U} / \mathrm{L}$ for men/women, respectively). Secondary outcomes were advanced fibrosis (via FIB-4 index) and factors associated with fibrosis. Results: The majority of patients were Asian (61.0\%) and hepatitis B e-antigen (HBeAg)-negative (90.4\%). Patients with CHB and NAFLD were older (57.2 vs. 49.5 years, $p<0.001)$, more likely male $(59.3 \%$ vs. $46.2 \%$, $p<0.001$ ), with higher percentages of advanced fibrosis (3.6\% vs. $2.6 \%, p<0.001)$ than those with $\mathrm{CHB}$ alone. CHBNAFLD patients were more likely to have elevated ALT than
\end{abstract}

karger@karger.com www.karger.com/ddi

Karger $\stackrel{\text { ' }}{5}$

GOPEN ACCESS
(C) 2021 The Author(s)

Published by S. Karger AG, Basel

This is an Open Access article licensed under the Creative Commons Attribution-NonCommercial-4.0 International License (CC BY-NC) (http://www.karger.com/Services/OpenAccessLicense), applicable to the online version of the article only. Usage and distribution for commercial purposes requires written permission. those with $\mathrm{CHB}$ only, but this difference was only significant among those with low hepatitis B virus (HBV) DNA (38.1\% vs. $25.6 \%, p<0.001)$, not those with higher HBV DNA (>2,000 IU/ $\mathrm{mL}$ ). After adjusting for HBeAg, HBV DNA, and diabetes, NAFLD was not independently associated with advanced fibrosis (odds ratio 1.18, 95\% confidence interval: 0.30-4.59, $p=0.81$ ). Discussion: CHB-NAFLD patients with HBV DNA below treatment threshold were more likely to have elevated ALT but not those with higher HBV DNA, suggesting that ALT threshold does not need to be raised for antiviral eligibility for CHB with NAFLD.

(C) 2021 The Author(s)

Published by S. Karger AG, Basel

\section{Introduction}

Nonalcoholic fatty liver disease (NAFLD) has quickly become the most common cause of chronic liver disease worldwide, owing to the rise in obesity and diabetes, with an estimated prevalence of $25 \%$ globally, $30 \%$ in Asia, and $33 \%$ in the USA [1-3]. Chronic infection with hepatitis B virus (HBV) is also common, affecting 257-290 million individuals worldwide and remains a major cause of liver-related morbidity and mortality due to cirrhosis and/ 
or hepatocellular carcinoma (HCC) $[4,5]$. In the US, 0.84-1.59 million individuals are estimated to have chronic hepatitis $B(\mathrm{CHB})[6,7]$, and about one-third may have NAFLD, as recently reported by a large study of 6,786 CHB patients from the US and Taiwan [8].

Currently, all professional society guidelines use the serum ALT level as a surrogate marker of hepatic inflammation and disease activity and recommend treatment when both ALT and HBV DNA levels are high $[9,10]$. In patients without cirrhosis, antiviral therapy is recommended when ALT is $>2 \times$ upper limits of normal (ULN) and HBV DNA is high $(>20,000 \mathrm{IU} / \mathrm{mL}$ for hepatitis B eantigen [HBeAg]-positive and $>2,000 \mathrm{IU} / \mathrm{mL}$ for $\mathrm{HBeAg}$ negative patients). The ULN for ALT for healthy individuals were first established to be $30 \mathrm{U} / \mathrm{L}$ for men and 19 U/L for women by Prati and colleagues [11]. For the purpose of treatment consideration, the $2018 \mathrm{CHB}$ guideline by the American Association for the Study of Liver Diseases (AASLD) recommends using $35 \mathrm{U} / \mathrm{L}$ and $25 \mathrm{U} / \mathrm{L}$ as the ULN for men and women, respectively, while the 2017 $\mathrm{CHB}$ guideline by the European Association for the Study of the Liver (EASL) indicates $40 \mathrm{U} / \mathrm{L}$ as the ULN for ALT without difference by sex $[9,10]$. However, current guidelines do not indicate different ALT treatment thresholds for CHB patients who also have NAFLD. Data characterizing ALT levels of CHB patients with NAFLD are also limited. Therefore, it is important to evaluate the impact of coexisting NAFLD on ALT levels of CHB patients.

Using data from a large, multiethnic nationwide cohort of the USA, we aimed to characterize and compare the distribution of ALT levels in untreated $\mathrm{CHB}$ patients with NAFLD to those in untreated CHB patients without NAFLD. We also aimed to compare the distribution of liver fibrosis among patients with and without NAFLD and identify factors associated with advanced fibrosis.

\section{Methods}

Study Design and Data Source

This was a retrospective analysis of adults ( $\geq 18$ years) with $\mathrm{CHB}$ with and without NAFLD from a large, nationwide dataset: Clinformatics ${ }^{\mathrm{TM}}$ Data Mart Database (OptumInsight, Eden Prairie, MN, USA) from 2003 to 2019. Optum is a large, de-identified administrative claims database from large national insurance providers with longitudinal health data of individuals and includes de-identified enrollee demographics (sex, age, and race/ethnicity), medical claims (diagnosis and procedure codes), results for outpatient laboratory tests drawn from national reference laboratories, and pharmacy claims on over 72 million unique individuals in all 50 continental states of the USA [12]. The data were provided by the Population Health Science Center at Stanford University, Cal-

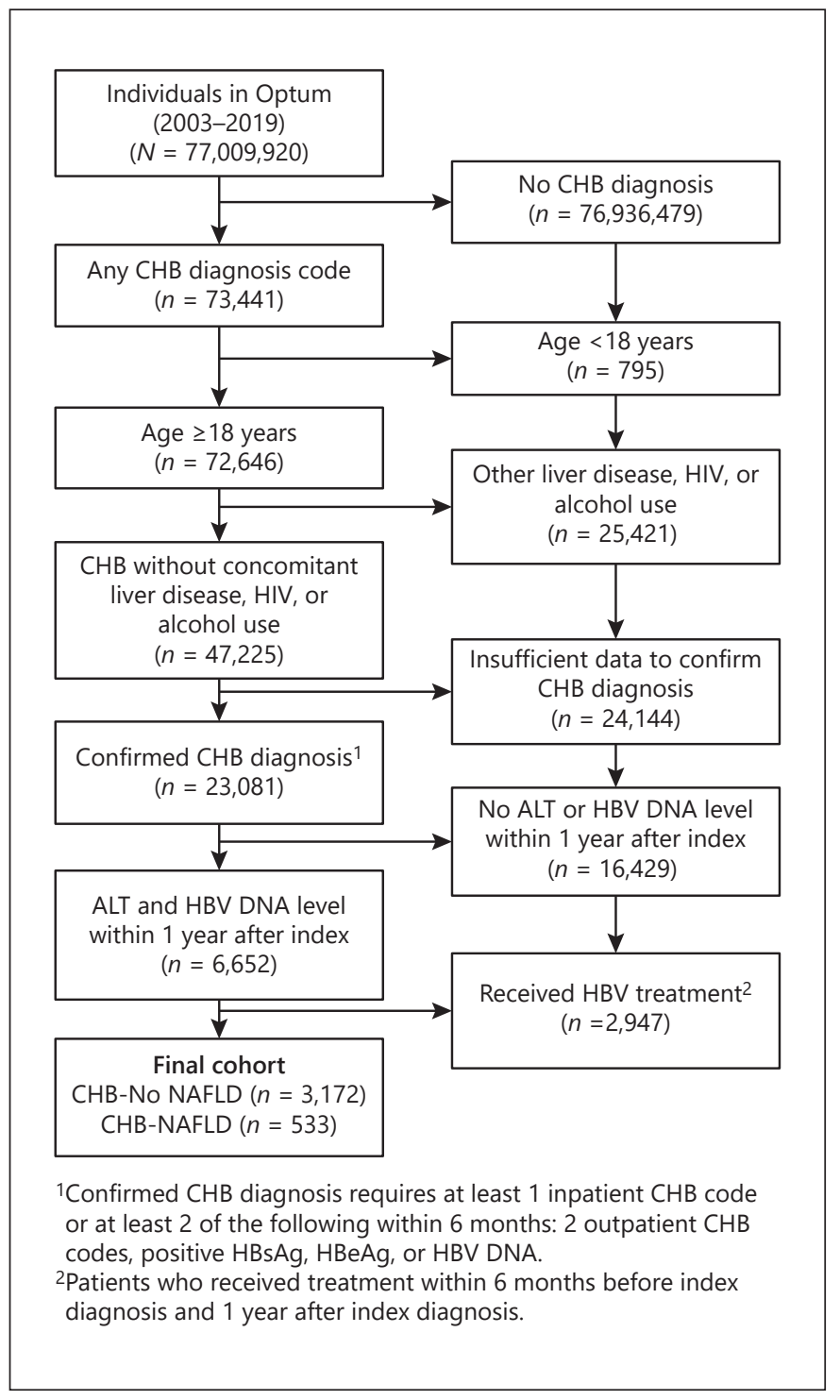

Fig. 1. Flowchart of patients included in the study.

ifornia, USA. The study was approved by the Institutional Review Board at Stanford University, Stanford, CA, USA. To protect the privacy of study participants, no data from groups of $<11$ can be shown in any study tables or result description.

\section{Study Patients}

All patients were at least 18 years of age. Patients were included if they had at least 1 International Classification of Diseases (ICD)9 or ICD-10 code for CHB, had at least one ALT result and one HBV DNA result within 1 year after index date, and had not received treatment for $\mathrm{CHB}$ during the 6 months prior to and within 1 year after index date. $\mathrm{CHB}$ diagnosis was confirmed if patients had at least 1 inpatient claim for CHB diagnosis or at least 2 of the following within 6 months: outpatient claim(s) for CHB diagnosis, positive $\mathrm{HBsAg}$, positive $\mathrm{HBeAg}$, or positive $\mathrm{HBV}$ DNA. CHB diagnosis codes included the ICD-9-CM codes for CHB (070.22 and 
Table 1. Demographic and clinical characteristics of patients with $\mathrm{CHB}$ with or without NAFLD

\begin{tabular}{|c|c|c|c|}
\hline Variables & $\begin{array}{l}\text { CHB-No NAFLD } \\
(n=3,172)\end{array}$ & $\begin{array}{l}\text { CHB-NAFLD } \\
(n=533)\end{array}$ & $p$ value \\
\hline Age $($ mean $\pm S D)$ & $49.5 \pm 14.9$ & $57.2 \pm 13.3$ & $<0.001$ \\
\hline Male & $1,465(46.2)$ & $316(59.3)$ & $<0.001$ \\
\hline \multicolumn{4}{|l|}{ Race/ethnicity } \\
\hline Asian & $1,901(59.9)$ & $360(67.5)$ & 0.002 \\
\hline Black & $290(9.1)$ & $27(5.1)$ & \\
\hline Hispanic & $146(4.6)$ & $28(5.3)$ & \\
\hline White & $431(13.6)$ & $60(11.3)$ & \\
\hline Unknown & $404(12.7)$ & $58(10.9)$ & \\
\hline \multicolumn{4}{|l|}{ Comorbidities } \\
\hline Dyslipidemia & $928(29.3)$ & $275(51.6)$ & $<0.001$ \\
\hline Hypertension & $809(25.5)$ & $233(43.7)$ & $<0.001$ \\
\hline Overweight & $133(4.2)$ & $72(13.5)$ & $<0.001$ \\
\hline Obese & $121(3.8)$ & $62(11.6)$ & $<0.001$ \\
\hline Smoking & $107(3.4)$ & $25(4.7)$ & $<0.001$ \\
\hline Diabetes & $425(13.4)$ & $137(25.7)$ & $<0.001$ \\
\hline Metabolic syndrome & $12(0.4)$ & $*$ & 0.09 \\
\hline Myocardial infarction & $24(0.8)$ & $*$ & 0.005 \\
\hline Peripheral vascular disease & $122(3.8)$ & $50(9.4)$ & $<0.001$ \\
\hline Cerebrovascular disease & $97(3.1)$ & $21(3.9)$ & $<0.001$ \\
\hline Renal impairment & $210(6.6)$ & $95(17.8)$ & $<0.001$ \\
\hline Chronic kidney disease & $95(3.0)$ & $27(5.1)$ & $<0.001$ \\
\hline Chronic pulmonary disease & $260(8.2)$ & $69(12.9)$ & $<0.001$ \\
\hline Osteoporosis & $175(5.5)$ & $66(12.4)$ & $<0.001$ \\
\hline Osteoarthritis & $287(9.0)$ & $93(17.4)$ & $<0.001$ \\
\hline
\end{tabular}

Values as mean $\pm \mathrm{SD}$ or $n(\%)$. CHB, chronic hepatitis B; NAFLD, nonalcoholic fatty liver disease. ${ }^{*}$ Data for individual rows not shown as per Stanford Center for Population Health Sciences requirement for data cells with $<11$ patients. $p$ values reflect analysis that included the subgroups not shown.
070.32) as well as the ICD-10-CM code, B18.1. CHB patients with NAFLD were identified with at least 1 inpatient or 2 outpatient claims for fatty liver using ICD-9-CM codes 571.8, 571.9, and 571.5 and ICD-10-CM codes K76.0 and K75.81. The index date was the first date of a CHB or NAFLD diagnosis code - whichever was later. Exclusion criteria were $\mathrm{CHB}$ treatment 6 months prior to and within 1 year after index date, diagnosis of other liver diseases, alcohol use (see online suppl. Table 1 at www. karger.com/doi/10.1159/000518645 for ICD-9/10 codes), and HIV infection.

\section{Study Variables and Outcomes}

The primary outcome was ALT level, classified as normal $(\leq 1 \times$ upper limit of normal; ULN) or elevated $(>1 \times \mathrm{ULN})$, with ULN defined as $35 \mathrm{U} / \mathrm{L}$ for men and $25 \mathrm{U} / \mathrm{L}$ for women per the current AASLD guidance [9]. As a sensitivity analysis, ULN was also defined as $30 \mathrm{U} / \mathrm{L}$ for men and $19 \mathrm{U} / \mathrm{L}$ for women as per Prati et al. [11] and prior AASLD guidelines and $40 \mathrm{U} / \mathrm{L}$ as per the EASL guideline $[10,13]$. We also stratified ALT data by low $(\leq 2,000 \mathrm{IU} / \mathrm{mL})$ or high $(>2,000 \mathrm{IU} / \mathrm{mL}) \mathrm{HBV}$ DNA levels. Laboratory tests included HBV e-Antigen, HBV DNA, HBV genotype, albumin, ALT, aspartate aminotransferase, alkaline phosphatase, gamma glutamyl transpeptidase, platelet count, creatinine, total bilirubin, hemoglobin A1c, fasting glucose, total cholesterol, high density lipoprotein, low density lipoprotein, and triglycerides.

Comorbidities were determined by ICD-9/10-CM codes and included several common chronic medical conditions, such as diabetes mellitus, dyslipidemia, hypertension, metabolic syndrome, smoking, cardiovascular disease (myocardial infarction, congestive heart failure, and peripheral vascular disease), renal impairment, chronic pulmonary disease, osteoporosis, and osteoarthritis. Advanced fibrosis was defined as a Fibrosis-4 (FIB-4) score $\geq 3.25$ [14]. Identification of anti-HBV medications (adefovir, entecavir, lamivudine, interferon- $\alpha$, pegylated interferon- $\alpha$, telbivudine, and tenofovir) among patients in Optum was captured from pharmaceutical claims.

\section{Statistical Analyses}

Categorical variables were evaluated using the $\chi^{2}$ test and reported as number and proportion (\%). Continuous variables were reported as mean \pm standard deviation and evaluated using either the Student $t$ test if data were normally distributed; otherwise nonparametric methods were used. Univariable and multivariable logistic regression analyses were performed to determine factors associated with advanced fibrosis. Statistical significance was defined with a 2 -sided test and a $p$ value of 0.05 . Statistical analyses were performed using $\mathrm{R}$ programing language ( $\mathrm{R}$ Foundation Inc; http://cran.r-project.org/) and Stata, version 16.1 (StataCorp). 
Table 2. Laboratory characteristics in patients with $\mathrm{CHB}$ with or without NAFLD

\begin{tabular}{|c|c|c|c|}
\hline & $\begin{array}{l}\text { CHB-No NAFLD } \\
(n=3,172)\end{array}$ & $\begin{array}{l}\text { CHB-NAFLD } \\
(n=533)\end{array}$ & $p$ value \\
\hline $\mathrm{ALT}, \mathrm{U} / \mathrm{L}$ & $21(16-30)$ & $26(18-39)$ & 0.50 \\
\hline \multicolumn{4}{|l|}{ ALT (ULN 35/25) } \\
\hline$\leq 1 \times \mathrm{ULN}$ & $2,309(72.8)$ & $328(61.5)$ & \multirow{2}{*}{$<0.001$} \\
\hline$>1 \times \mathrm{ULN}$ & $863(27.2)$ & $205(38.5)$ & \\
\hline \multicolumn{4}{|l|}{ ALT (ULN 35/25) } \\
\hline$<1 \times \mathrm{ULN}$ & $2,309(72.8)$ & $328(61.5)$ & \multirow{3}{*}{$<0.001$} \\
\hline $1-2 \times U L N$ & $693(21.8)$ & $156(29.3)$ & \\
\hline$>2 \times \mathrm{ULN}$ & $170(5.4)$ & $49(9.2)$ & \\
\hline \multicolumn{4}{|l|}{ ALT (ULN 30/19) } \\
\hline$\leq 1 \times \mathrm{ULN}$ & $1,780(56.1)$ & $244(45.8)$ & \multirow{2}{*}{$<0.001$} \\
\hline$>1 \times \mathrm{ULN}$ & $1,392(43.9)$ & $289(54.2)$ & \\
\hline \multicolumn{4}{|l|}{ ALT (ULN 40) } \\
\hline$\leq 1 \times \mathrm{ULN}$ & $2,725(85.9)$ & $402(75.4)$ & \multirow{2}{*}{$<0.001$} \\
\hline$>1 \times \mathrm{ULN}$ & $447(14.1)$ & $131(24.6)$ & \\
\hline \multicolumn{4}{|l|}{ HBV DNA, IU/mL } \\
\hline$\leq 2,000 \mathrm{IU} / \mathrm{mL}$ & $2,816(88.8)$ & $480(90.1)$ & \multirow[t]{2}{*}{0.38} \\
\hline$>2,000 \mathrm{IU} / \mathrm{mL}$ & $356(11.2)$ & $53(9.9)$ & \\
\hline HBeAg-positive $(n=1,653 ; 234)$ & $161(9.7)$ & $20(8.5)$ & 0.56 \\
\hline \multicolumn{4}{|l|}{ FIB-4 - advanced fibrosis $(n=1,890 ; 440)$} \\
\hline Low probability & $1,275(67.5)$ & $225(51.1)$ & \multirow{3}{*}{$<0.001$} \\
\hline Indeterminate & $563(29.8)$ & $199(45.2)$ & \\
\hline High probability & $52(2.6)$ & $16(3.6)$ & \\
\hline Albumin, g/dL $(n=3,128 ; 528)$ & $4.4 \pm 0.3$ & $4.4 \pm 0.3$ & $<0.001$ \\
\hline Aspartate aminotransferase, U/L $(n=2,829 ; 527)$ & $27.2 \pm 33.6$ & $28.9 \pm 24.6$ & 0.29 \\
\hline Alkaline phosphatase, $\mathrm{U} / \mathrm{L}(n=3,134 ; 529)$ & $67.5 \pm 26.2$ & $70.9 \pm 39.7$ & 0.01 \\
\hline Gamma glutamyl transferase, U/L $(n=359 ; 86)$ & $27.6 \pm 61.3$ & $35.5 \pm 40.7$ & 0.26 \\
\hline Platelet, $10^{9} / \mathrm{L}(n=2,503 ; 441)$ & $228.9 \pm 59.7$ & $225.0 \pm 61.6$ & 0.21 \\
\hline Total bilirubin, $\mathrm{mg} / \mathrm{dL}(n=3,140 ; 530)$ & $0.6 \pm 0.5$ & $0.6 \pm 0.4$ & 0.01 \\
\hline Serum creatinine, $\mathrm{mg} / \mathrm{dL}(n=2,791 ; 486)$ & $0.9 \pm 0.5$ & $0.9 \pm 0.2$ & 0.78 \\
\hline HbAlc, $\%(n=946 ; 259)$ & $6.1 \pm 1.1$ & $6.3 \pm 1.1$ & 0.01 \\
\hline Glucose, $\mathrm{mg} / \mathrm{dL}(n=120 ; 24)$ & $94.4 \pm 38.2$ & $120.0 \pm 48.1$ & 0.01 \\
\hline Total cholesterol, mg/dL $(n=1,929 ; 395)$ & $184.9 \pm 36.4$ & $185.7 \pm 38.5$ & 0.69 \\
\hline HDL cholesterol, mg/dL $(n=1,834 ; 381)$ & $56.4 \pm 16.1$ & $50.6 \pm 13.4$ & $<0.001$ \\
\hline LDL cholesterol, mg/dL $(n=1,872 ; 386)$ & $106.1 \pm 32.0$ & $105.8 \pm 33.2$ & 0.88 \\
\hline Triglycerides, mg/dL $(n=1,896 ; 391)$ & $114.3 \pm 74.9$ & $151.3 \pm 91.4$ & $<0.001$ \\
\hline
\end{tabular}

Values as mean $\pm \mathrm{SD}$ or median (IQR) or $n(\%)$. CHB, chronic hepatitis B; NAFLD, nonalcoholic fatty liver disease; ULN, upper limits of normal; HBV, hepatitis B virus; HBeAg, hepatitis B e-antigen; FIB-4, Fibrosis-4.

\section{Results}

Patient Characteristics and Overall ALT Distribution

In total, our study included 3,705 CHB patients: 533 with NAFLD and 3,172 without NAFLD (Fig. 1). The majority of patients were Asian (61.0\%; Table 1). Compared to patients with $\mathrm{CHB}$ only, $\mathrm{CHB}$ patients with NAFLD were older ( $57.2 \pm 13.3$ vs. $49.5 \pm 14.9$ years, $p<0.001)$, more likely male ( $59.3 \%$ vs. $46.2 \%, p<0.001)$ and had significantly higher rates of comorbidities (Table 2).
The distribution of $\mathrm{HBeAg}$ positivity was similar in both groups ( $9.7 \%$ vs. $8.5 \%, p=0.56)$. Compared to $\mathrm{CHB}$ patients without NAFLD, CHB patients with NAFLD had a similar proportion of patients with low $(\leq 2,000 \mathrm{IU} / \mathrm{mL})$ HBV DNA ( $90.1 \%$ vs. $88.8 \%, p=0.38$ ) but higher proportion of patients with elevated ALT (38.5\% vs. $27.2 \%, p<$ 0.001 , for $>1 \times$ ULN, with ULN defined as $35 / 25 \mathrm{U} / \mathrm{L}$ ). Additional analysis was also performed using an alternative cutoff for ULN as suggested by Prati et al. [10, 11] (30 and 19) and EASL (40) as shown in Table 2. In addition, patients with $\mathrm{CHB}$ and NAFLD were slightly more likely 
Table 3. ALT levels in patients with $\mathrm{CHB}$ with or without NAFLD by the HBV DNA level $(\leq 2,000 \mathrm{IU} / \mathrm{mL}$ vs. $>2,000 \mathrm{IU} /$ $\mathrm{mL})$

\begin{tabular}{|c|c|c|c|}
\hline & $\begin{array}{l}\text { CHB-No NAFLD } \\
(n=3,172)\end{array}$ & $\begin{array}{l}\text { CHB-NAFLD } \\
(n=533)\end{array}$ & $p$ value \\
\hline \multicolumn{4}{|l|}{ HBV DNA } \\
\hline$\leq 2,000 \mathrm{IU} / \mathrm{mL}$ & $2,816(88.8)$ & $480(90.1)$ & \multirow{2}{*}{0.38} \\
\hline$>2,000 \mathrm{IU} / \mathrm{mL}$ & $356(11.2)$ & $53(9.9)$ & \\
\hline $\mathrm{HBV}$ DNA $\leq 2,000 \mathrm{IU} / \mathrm{mL}$ & $(n=2,816)$ & $(n=480)$ & \\
\hline \multicolumn{4}{|l|}{ ALT (ULN 35/25) } \\
\hline$\leq 1 \times \mathrm{ULN}$ & $2,095(74.4)$ & $297(61.9)$ & \multirow{2}{*}{$<0.001$} \\
\hline$>1 \times \mathrm{ULN}$ & $721(25.6)$ & $183(38.1)$ & \\
\hline \multicolumn{4}{|l|}{ ALT (ULN 35/25) } \\
\hline$<1 \times$ ULN & $2,095(74.4)$ & $297(61.9)$ & \multirow{3}{*}{$<0.001$} \\
\hline $1-2 \times$ ULN & $595(21.1)$ & $139(29.0)$ & \\
\hline$>2 \times \mathrm{ULN}$ & $126(4.5)$ & $44(9.2)$ & \\
\hline \multicolumn{4}{|l|}{ ALT (ULN 30/19) } \\
\hline$\leq 1 \times$ ULN & $1,613(57.9)$ & $225(46.9)$ & \multirow{2}{*}{$<0.001$} \\
\hline$>1 \times \mathrm{ULN}$ & $1,185(42.1)$ & $255(53.1)$ & \\
\hline \multicolumn{4}{|l|}{ ALT (ULN 40) } \\
\hline$\leq 1 \times \mathrm{ULN}$ & $2,451(87.0)$ & $361(75.2)$ & \multirow{2}{*}{$<0.001$} \\
\hline$>1 \times \mathrm{ULN}$ & $365(13.0)$ & $119(24.8)$ & \\
\hline $\mathrm{HBV}$ DNA > 2,000 IU/mL & $(n=356)$ & $(n=53)$ & \\
\hline \multicolumn{4}{|l|}{ ALT (ULN 35/25) } \\
\hline$\leq 1 \times \mathrm{ULN}$ & $214(60.1)$ & $31(58.5)$ & \multirow{2}{*}{0.82} \\
\hline$>1 \times \mathrm{ULN}$ & $142(39.9)$ & $22(41.5)$ & \\
\hline \multicolumn{4}{|l|}{ ALT (ULN 35/25) } \\
\hline$<1 \times$ ULN & $214(60.1)$ & $31(58.5)$ & \multirow{3}{*}{0.71} \\
\hline $1-2 \times$ ULN & $98(27.5)$ & $*$ & \\
\hline$>2 \times U L N$ & $44(12.4)$ & $*$ & \\
\hline \multicolumn{4}{|l|}{ ALT (ULN 30/19) } \\
\hline$\leq 1 \times \mathrm{ULN}$ & $149(41.9)$ & $19(35.8)$ & \multirow{2}{*}{0.41} \\
\hline$>1 \times \mathrm{ULN}$ & $207(58.1)$ & $34(64.2)$ & \\
\hline \multicolumn{4}{|l|}{ ALT (ULN 40) } \\
\hline$\leq 1 \times \mathrm{ULN}$ & $274(77.0)$ & $41(77.4)$ & \multirow{2}{*}{0.95} \\
\hline$>1 \times \mathrm{ULN}$ & $82(23.0)$ & $12(22.6)$ & \\
\hline
\end{tabular}

Values as mean $\pm \mathrm{SD}$ or $n(\%)$. CHB, chronic hepatitis B; NAFLD, nonalcoholic fatty liver disease; ULN, upper limits of normal; HBV, hepatitis B virus. * Data for individual rows not shown as per Stanford Center for Population Health Sciences requirement for data cells with $<11$ patients. The combined data of the 2 rows are 22 patients $(41.5 \%)$. $p$ values reflect analysis that included the subgroups not shown. to have advanced fibrosis though the proportion of patients with advanced fibrosis was low in both groups (3.6\% vs. $2.6 \%, p<0.001)$ (Table 2 ).

\section{ALT Levels, Stratified by HBV DNA Level, and HBeAg Positivity}

Among patients with low HBV DNA $(\leq 2,000 \mathrm{IU} / \mathrm{mL})$ and any $\mathrm{HBeAg}$ status, $\mathrm{CHB}$ patients with NAFLD were more likely to have elevated ALT, compared to those with CHB only ( $38.1 \%$ vs. $25.6 \%$ for ULN defined as $35 / 25$ $\mathrm{U} / \mathrm{L}, p<0.001$; Table 3). However, among patients with high HBV DNA $(>2,000 \mathrm{IU} / \mathrm{mL})$, there was no statistically significant difference in the proportion of patients with ALT elevation in patients with $\mathrm{CHB}$ only versus CHB-NAFLD ( $41.5 \%$ vs. $39.9 \%, p=0.82)$.

Similar findings were observed in stratified analysis of patients with negative $\mathrm{HBeAg}$. $\mathrm{HBeAg}$-negative $\mathrm{CHB}$ patients with NAFLD, and low HBV DNA $(\leq 2,000 \mathrm{IU} / \mathrm{mL})$ were more likely to have elevated ALT levels compared to those without NAFLD ( $40.7 \%$ vs. $25.7 \%, p<0.001$; Table 4 ), while the 2 groups had similar ALT distribution among those with HBV DNA levels $>2,000 \mathrm{IU} / \mathrm{mL}$. Stratified analysis for patients with positive $\mathrm{HBeAg}$ could not be performed due to small sample size, with major subgroup sizes $<11$ (the lowest number allowed to be shown by the Stanford Population Health Science Center). 
Table 4. ALT levels in HBeAg-negative patients by the HBV DNA level

\begin{tabular}{|c|c|c|c|}
\hline & $\begin{array}{l}\text { CHB-No NAFLD } \\
(n=1,492)\end{array}$ & $\begin{array}{l}\text { CHB-NAFLD } \\
(n=214)\end{array}$ & $p$ value \\
\hline $\begin{array}{l}\mathrm{HBV} \text { DNA } \leq 2,000 \mathrm{IU} / \mathrm{mL} \\
\text { ALT }(\mathrm{ULN} 35 / 25)\end{array}$ & $(n=1,345)$ & $(n=194)$ & \\
\hline $\begin{array}{l}\leq 1 \times \mathrm{ULN} \\
>1 \times \mathrm{ULN}\end{array}$ & $\begin{array}{r}1,000(74.3) \\
345(25.7)\end{array}$ & $\begin{array}{r}115(59.3) \\
79(40.7)\end{array}$ & $<0.001$ \\
\hline \multicolumn{4}{|l|}{ ALT (ULN 35/25) } \\
\hline$<1 \times \mathrm{ULN}$ & $1,000(74.3)$ & $115(59.3)$ & \multirow{3}{*}{$<0.001$} \\
\hline $1-2 \times U L N$ & $296(22.0)$ & $60(30.9)$ & \\
\hline$>2 \times U L N$ & $49(3.6)$ & $19(9.8)$ & \\
\hline \multicolumn{4}{|l|}{ ALT (ULN 30/19) } \\
\hline$\leq 1 \times \mathrm{ULN}$ & $764(56.8)$ & $86(44.3)$ & \multirow{2}{*}{0.001} \\
\hline$>1 \times \mathrm{ULN}$ & $581(43.2)$ & $108(55.7)$ & \\
\hline \multicolumn{4}{|l|}{ ALT (ULN 40) } \\
\hline$\leq 1 \times \mathrm{ULN}$ & $1,178(87.6)$ & $144(74.2)$ & \multirow{2}{*}{$<0.001$} \\
\hline$>1 \times \mathrm{ULN}$ & $167(12.4)$ & $50(25.8)$ & \\
\hline $\mathrm{HBV}$ DNA > 2,000 IU/mL & $(n=147)$ & $(n=20)$ & \\
\hline \multicolumn{4}{|l|}{ ALT (ULN 35/25) } \\
\hline$\leq 1 \times \mathrm{ULN}$ & $91(61.9)$ & $*$ & \multirow{2}{*}{0.55} \\
\hline$>1 \times \mathrm{ULN}$ & $56(38.1)$ & $*$ & \\
\hline \multicolumn{4}{|l|}{ ALT (ULN 35/25) } \\
\hline$<1 \times$ ULN & $91(61.9)$ & $*$ & \multirow{3}{*}{0.09} \\
\hline $1-2 \times U L N$ & $38(25.9)$ & $*$ & \\
\hline$>2 \times \mathrm{ULN}$ & $18(12.2)$ & $*$ & \\
\hline \multicolumn{4}{|l|}{ ALT (ULN 30/19) } \\
\hline$\leq 1 \times \mathrm{ULN}$ & $61(41.5)$ & $*$ & \multirow{2}{*}{0.33} \\
\hline$>1 \times \mathrm{ULN}$ & $86(58.5)$ & * & \\
\hline \multicolumn{4}{|l|}{ ALT (ULN 40) } \\
\hline$\leq 1 \times \mathrm{ULN}$ & $116(78.9)$ & $*$ & \multirow{2}{*}{0.91} \\
\hline$>1 \times \mathrm{ULN}$ & $31(21.1)$ & $*$ & \\
\hline
\end{tabular}

Values as mean $\pm \mathrm{SD}$ or $n(\%)$. CHB, chronic hepatitis B; NAFLD, nonalcoholic fatty liver disease; ULN, upper limits of normal; $\mathrm{HBV}$, hepatitis B virus; $\mathrm{HBeAg}$, hepatitis B e-antigen. ${ }^{*}$ Data for individual rows not shown as per Stanford Center for Population Health Sciences requirement for data cells with $<11$ patients. $p$ values reflect analysis that included the subgroups not shown.

Table 5. Factors associated with advanced fibrosis in $\mathrm{CHB}$ patients

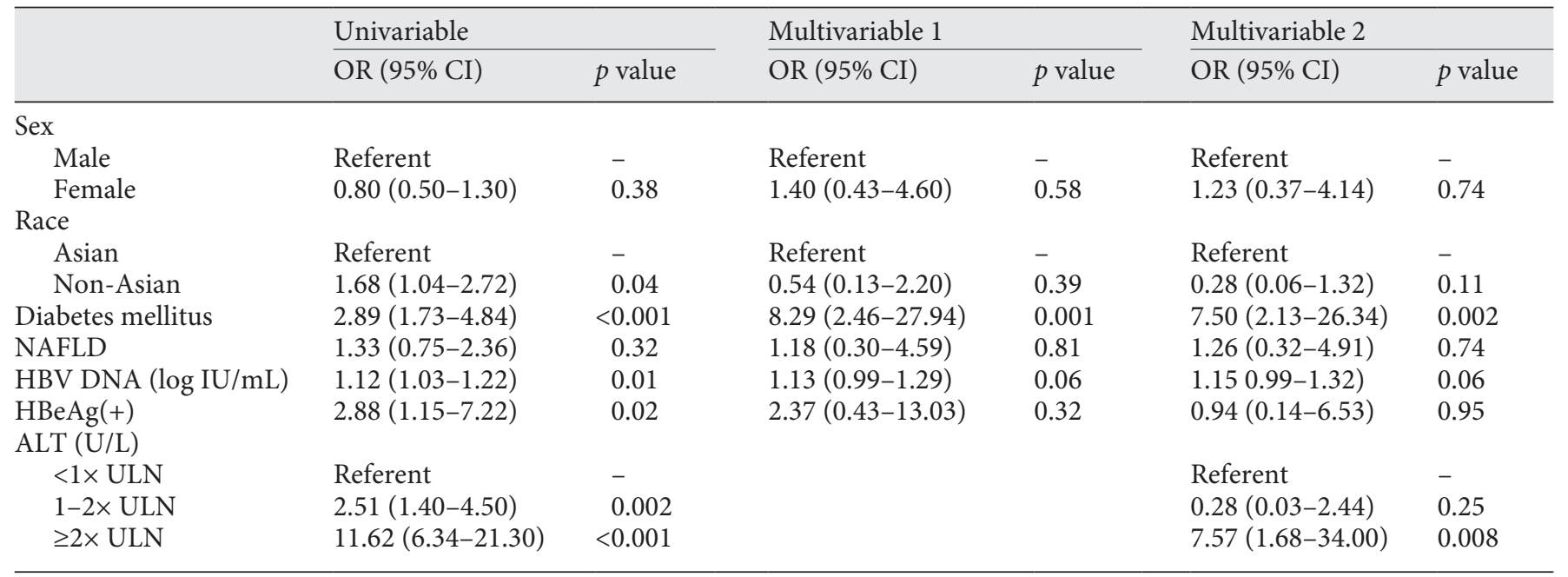




\section{Factors Associated with Advanced Fibrosis}

In the main multivariable logistic regression model (Table 5, Model 1), after adjusting for sex, race/ethnicity, diabetes mellitus, HBV DNA, and HBeAg, only diabetes mellitus (odds ratio [OR] 8.29, 95\% confidence interval $[C I]: 2.46-27.94, p=0.001)$ was a significant independent predictor for advanced fibrosis but not NAFLD (OR 1.18, 95\% CI: $0.30-4.59, p=0.81)$. When ALT was added to an alternative model (Model 2) for advanced fibrosis, diabetes mellitus (OR 7.50, 95\% CI: 2.13-26.34, $p=0.002$ ) and ALT $\geq 2 \times$ ULN (OR 7.57, 95\% CI: 1.68-34.00, $p=0.008$ ) were significant predictors but not NAFLD (OR 1.26, 95\% CI: 0.32-4.91, $p=0.74$ ). In both models (with and without ALT), a higher HBV DNA level was at borderline significance $(p=0.06)$.

\section{Discussion}

Using a large database of insurance claims with link to laboratory results in the United States (2003-2019), we compared ALT levels in untreated, multiethnic chronic HBV patients with $(n=533)$ and without concomitant NAFLD $(n=3,172)$. Furthermore, we stratified patients according to HBeAg status and HBV DNA levels. We found overall higher rates of elevated ALT levels among patients with HBV and NAFLD than those with HBV alone $(38.5 \%$ vs. $27.2 \%>1 \times$ ULN, with ULN defined as $35 / 25)$, but only among those with low HBV DNA $(\leq 2,000$ $\mathrm{IU} / \mathrm{mL})$ and not those with higher HBV DNA $(>2,000 \mathrm{IU} /$ $\mathrm{mL}$ ). While ALT may not be an ideal criterion to select for candidates who may benefit from antiviral therapy, it is currently one of the major criteria used by professional society guidelines to guide treatment decision, and the results of our study can inform current practice as well as future practice guidelines.

Prior studies have shown no difference in ALT or HBV DNA levels [15-18], but these were generally of small sample size and of patients who had undergone liver biopsy. More recently, larger population studies from Asia have shown higher ALT levels in patients with CHB and concomitant NAFLD but without stratified analysis by HBV DNA levels, limiting their conclusions [19-21]. In our study, the higher rate of ALT elevation among patients with concurrent $\mathrm{CHB}$ and NAFLD in stratified analysis of low HBV DNA $(\leq 2,000 \mathrm{IU} / \mathrm{mL})$ patients may be due to the fact that HBV is less active in these patients and that ALT elevation is primarily driven by NAFLD disease activity. This is consistent with a populationbased cohort study from Alaska, which identified NAFLD as one of the most common causes of ALT elevation (24.7\%) in chronic HBV patients with persistently low viral load $(<2,000 \mathrm{IU} / \mathrm{mL})$ [22]. Conversely, among patients with high HBV DNA levels, $\mathrm{HBV}$ is presumably the main driver for inflammation rather than NAFLD, and thus consequently, the similar distribution of ALT among patients with $\mathrm{CHB}$ alone and CHB with NAFLD. This finding suggests that ALT threshold for antiviral therapy for $\mathrm{CHB}$ patients with NAFLD may not need to be raised.

Both CHB and NAFLD independently increase the risk for fibrosis, cirrhosis, and HCC $[1,13]$. The interplay between CHB and NAFLD however remains complex and controversial. While several studies have found no synergistic interaction between NAFLD and viral factors, such as HBV DNA and HBeAg [16, 17, 23, 24], a few prior studies have also reported increased risk of cirrhosis and HCC in patients with CHB and concurrent NAFLD compared to CHB alone [20, 25-27]. However, the majority of these studies included patients evaluated at tertiary centers and/or those selected for liver biopsy, biasing towards patients with advanced disease. On the other hand, it has been suggested that HBV may have a protective effect against NAFLD and lower rates of NAFLD development among HBV-infected patients [19, 21, 28-33]. Meanwhile, NAFLD may promote viral clearance in patients with $\mathrm{CHB}$, with decreased HBV DNA, HBsAg, and HBeAg levels in transgenic mice with NAFLD [34]. Indeed, onset of HBV seroclearance has been found to be earlier in patients with $\mathrm{CHB}$ and concurrent hepatic steatosis, as compared to those without steatosis, and higher rates of HBsAg seroclearance have been observed in patients with $\mathrm{CHB}$ and NAFLD than in patients with $\mathrm{CHB}$ only $[8,35]$. One explanation for increased viral clearance in CHB patients with concurrent NAFLD may lie in the increased expression of Fas receptors on the surface of hepatocytes in $\mathrm{CHB}$ patients with NASH, which thereby facilitate apoptosis [36]. Other favorable outcomes such as reduced risk of cirrhosis and HCC have also been reported in a large observational study with long-term follow-up among CHB patients with concurrent fatty liver compared to $\mathrm{CHB}$ patients without fatty liver [8]. In the current study, we found slightly higher rates of advanced fibrosis, as predicted by FIB-4, in patients with $\mathrm{CHB}$ and NAFLD, than in those with CHB alone (3.6\% vs. $2.6 \%$ ), though the percentages of patients with advanced fibrosis were relatively small in both groups.

There are several limitations to our study. Data were collected from insurance claims and may be subject to miscoding [37]. However, for the identification of our primary study cohort of $\mathrm{CHB}$ patients, we added confir- 
matory laboratory data with $\mathrm{HBs} \mathrm{Ag}, \mathrm{HBeAg}$, and/or HBV DNA to avoid miscoding of CHB diagnosis. Our study also suffers inherent limitation of a retrospective study design such as missing data, and available laboratory data were limited to those that were processed by a vendor with whom the insurance plan was contracted. We only included patients who had not received HBV antiviral therapy, potentially selecting for patients with lower ALT levels and with a lower likelihood of having advanced fibrosis, as those with higher ALT or advanced fibrosis/cirrhosis would be more likely to meet criteria for starting HBV treatment. The majority of patients had relatively low HBV DNA levels, and therefore, these results may not be generalizable to patients with higher HBV DNA levels. ALT data were analyzed at a single time point, closest to patient's index date, rather than analyzed serially. However, we used standardized and recommended cutoff values for ULN, independent of local laboratory normal ranges, and the study patients represent a real-world CHB patient cohort drawn from a diverse, nationwide, multiethnic population of the USA. Given the smaller number of HBeAg-positive patients in our study, subgroup analysis of ALT level of these patients is limited. More data are needed on HBeAg-positive patients. Finally, fibrosis was determined noninvasively using FIB-4, which is commonly done for this type of study. FIB- 4 has limitations in determining fibrosis in $\mathrm{CHB}$ patients and can underestimate the level of fibrosis, which could be one of the reasons for the low prevalence of advanced fibrosis in our study [38], though this low prevalence could also be due to the fact that our study cohort was a nationwide cohort inclusive of community-based patients rather than just referral patients from tertiary care research centers and that our study cohort only included treatment-naive untreated patients. FIB- 4 and most noninvasive biomarkers to detect fibrosis have not been validated in CHB patients with concomitant NAFLD. Therefore, our finding regarding fibrosis in $\mathrm{HBV}$ patients should be interpreted with caution. Further studies using other methods of assessing fibrosis in HBV as compared to HBV-NAFLD patients are needed.

\section{Conclusion}

We found higher rates of ALT elevation among CHB patients with low HBV DNA $(\leq 2,000 \mathrm{IU} / \mathrm{mL})$ and concurrent NAFLD than in those without NAFLD but not among patients with high HBV DNA $(>2,000 \mathrm{IU} / \mathrm{mL})$. This suggests that among patients with high HBV DNA meeting threshold for antiviral treatment, ALT threshold does not need to be raised by the presence of NAFLD, especially for HBeAg-negative patients. Further studies are needed to better characterize the distribution of ALT for HBeAg-positive patients, the effects of NAFLD on serial ALT changes in $\mathrm{CHB}$, as well as the impact of $\mathrm{CHB}$ and HBV DNA levels on development of NAFLD.

\section{Statement of Ethics}

The study was approved by the Institutional Review Board at Stanford University, Stanford, CA, USA, study protocol \# 13927. Informed consent was not required as data were retrospective and anonymized.

\section{Conflict of Interest Statement}

Christine Y. Chang, Leslie Kam, and Nolan Dang have nothing to disclose. Ramsey Cheung received research support from Gilead. Mindie H. Nguyen received research support from Glycotest, Gilead, Enanta, Pfizer, Vir, B.K. Kee Foundation, and National Cancer Institute, and served in the advisory board or as a consultant in Intercept, Novartis, Spring Bank, Gilead, Janssen, Eisai, Bayer, Laboratory of Advanced Medicine, Helio Health, and Eli Lilly.

\section{Funding Sources}

There are no external funding sources to disclose.

\section{Author Contributions}

Dr. Mindie H. Nguyen was the guarantor of the article. Christine Y. Chang contributed to study design, data analysis and interpretation, and drafting of the manuscript. Leslie Kam contributed to data analysis, data interpretation, and participated in the drafting of the manuscript. Nolan Dang contributed to data analysis, data interpretation, and review of the manuscript. Ramsey Cheung contributed to study design, data interpretation, and critical revision of the manuscript. Mindie H. Nguyen contributed to concept development, study design, data analysis and interpretation, and participated in the drafting and critical revision of the manuscript. All the authors identified above have critically reviewed the article and approved the final version of this article, including the authorship statement.

\section{Data Availability Statement}

All data generated or analyzed during this study were available from Clinformatics ${ }^{\mathrm{TM}}$ Data Mart Database (OptumInsight, Eden Prairie, MN, USA) via Stanford Population Health Sciences Center. Further inquiries regarding data to support the findings of the study can be directed to the corresponding author. 


\section{References}

1 Younossi ZM, Koenig AB, Abdelatif D, Fazel Y, Henry L, Wymer M. Global epidemiology of nonalcoholic fatty liver disease-Meta-analytic assessment of prevalence, incidence, and outcomes. Hepatology. 2016;64: 73-84.

2 Li J, Zou B, Yeo YH, Feng Y, Xie X, Lee DH, et al. Prevalence, incidence, and outcome of non-alcoholic fatty liver disease in Asia, 1999-2019: a systematic review and metaanalysis. Lancet Gastroenterol Hepatol. 2019; 4:389-98.

3 Le MH, Yeo YH, Cheung R, Wong VW, Nguyen $\mathrm{MH}$. Ethnic influence on nonalcoholic fatty liver disease prevalence and lack of disease awareness in the United States, 2011-2016. J Intern Med. 2020;287:71122.

4 World Health Organization. Hepatitis B. Available from: http://www.who.int/mediacentre/ factsheets/fs204/en Accessed 2021 Feb 8

5 Razavi-Shearer D, Gamkrelidze I, Nguyen $\mathrm{MH}$, Chen D-S, Van Damme P, Abbas Z, et al. Global prevalence, treatment, and prevention of hepatitis B virus infection in 2016: a modelling study. Lancet Gastroenterol Hepatol. 2018;3:383-403.

6 Le MH, Yeo YH, Cheung R, Henry L, Lok AS, Nguyen MH. Chronic hepatitis B prevalence among foreign-born and U.S. born adults in the United States, 1999-2016. Hepatology. 2020;71:431-43.

7 Lim JK, Nguyen MH, Kim WR, Gish R, Perumalswami P, Jacobson IM. Prevalence of chronic hepatitis B virus infection in the United States. Am J Gastroenterol. 2020;115: 1429-38.

8 Li J, Yang HI, Yeh ML, Le MH, Le AK, Yeo $\mathrm{YH}$, et al. Association between fatty liver and cirrhosis, hepatocellular carcinoma, and HBsAg seroclearance in chronic hepatitis B. J Infect Dis. 2020;0:1-14.

9 Terrault NA, Lok ASF, McMahon BJ, Chang KM, Hwang JP, Jonas MM, et al. Update on prevention, diagnosis, and treatment of chronic hepatitis B: AASLD 2018 hepatitis B guidance. Hepatology. 2018;67:1560-99.

10 European Association for the Study of the Liver. EASL 2017 clinical practice guidelines on the management of hepatitis B virus infection. J Hepatol. 2017;67:370-98.

11 Prati D, Taioli E, Zanella A, Della Torre E, Butelli S, Del Vecchio E, et al. Updated definitions of healthy ranges for serum alanine aminotransferase levels. Ann Intern Med. 2002; 137:1-10.

12 Wallace PJ, Shah ND, Dennen T, Bleicher PA, Bleicher PD, Crown WH. Optum labs: building a novel node in the learning health care system. Health Aff. 2014;33:1187-94.

13 Terrault NA, Bzowej NH, Chang KM, Hwang JP, Jonas MM, Murad MH, et al. AASLD guidelines for treatment of chronic hepatitis B. Hepatology. 2016;63:261-83.
14 Sterling RK, Lissen E, Clumeck N, Sola R, Correa MC, Montaner J, et al. Development of a simple noninvasive index to predict significant fibrosis in patients with $\mathrm{HIV} / \mathrm{HCV}$ coinfection. Hepatology. 2006;43:1317-25.

15 Tsochatzis E, Papatheodoridis GV, Manesis EK, Chrysanthos N, Kafiri G, Archimandritis AJ. Hepatic steatosis in chronic hepatitis B develops due to host metabolic factors: a comparative approach with genotype 1 chronic hepatitis C. Dig Liver Dis. 2007;39:936-42.

16 Peng D, Han Y, Ding H, Wei L. Hepatic steatosis in chronic hepatitis B patients is associated with metabolic factors more than viral factors. J Gastroenterol Hepatol. 2008;23: 1082-8.

17 Minakari M, Molaei M, Shalmani HM, Mohammad Alizadeh AH, Jazi AH, Naderi N, et al. Liver steatosis in patients with chronic hepatitis B infection: host and viral risk factors. Eur J Gastroenterol Hepatol. 2009;21: 512-6.

18 Yun JW, Cho YK, Park JH, Kim HJ, Park DI, Sohn CI, et al. Hepatic steatosis and fibrosis in young men with treatment-naïve chronic hepatitis B. Liver Int. 2009;29:878-83.

19 Cheng YL, Wang YJ, Kao WY, Chen PH, Huo $\mathrm{TI}$, Huang $\mathrm{YH}$, et al. Inverse association between hepatitis B virus infection and fatty liver disease: a large-scale study in populations seeking for check-up. PLoS One. 2013;8: e72049.

20 Choi HSJ, Brouwer WP, Zanjir WMR, de Man RA, Feld JJ, Hansen BE, et al. Nonalcoholic steatohepatitis is associated with liverrelated outcomes and all-cause mortality in chronic hepatitis B. Hepatology. 2020;71: 539-48.

21 Hui RWH, Seto WK, Cheung KS, Mak LY, Liu $\mathrm{KSH}$, Fung J, et al. Inverse relationship between hepatic steatosis and hepatitis B viremia: results of a large case-control study. J Viral Hepat. 2018;25:97-104.

22 Spradling PR, Bulkow L, Teshale EH, Negus S, Homan C, Simons B, et al. Prevalence and causes of elevated serum aminotransferase levels in a population-based cohort of persons with chronic hepatitis B virus infection. J Hepatol. 2014;61:785-91.

23 Zhu L, Jiang J, Zhai X, Baecker A, Peng H, Qian J, et al. Hepatitis B virus infection and risk of non-alcoholic fatty liver disease: a population-based cohort study. Liver Int. 2019; 39:70-80.

24 Pais R, Rusu E, Zilisteanu D, Circiumaru A Micu L, Voiculescu M, et al. Prevalence of steatosis and insulin resistance in patients with chronic hepatitis $\mathrm{B}$ compared with chronic hepatitis $\mathrm{C}$ and non-alcoholic fatty liver disease. Eur J Intern Med. 2015;26:30-6.

25 Chan AW, Wong GL, Chan HY, Tong JH, Yu $\mathrm{YH}$, Choi PC, et al. Concurrent fatty liver increases risk of hepatocellular carcinoma among patients with chronic hepatitis B. J Gastroenterol Hepatol. 2017;32:667-76.
26 Peleg N, Issachar A, Sneh Arbib O, CohenNaftaly M, Braun M, Leshno M, et al. Liver steatosis is a strong predictor of mortality and cancer in chronic hepatitis B regardless of viral load. JHEP Rep. 2019;1:9-16.

27 Wong GL, Chan HL, Yu Z, Chan AW, Choi PC, Chim AM, et al. Coincidental metabolic syndrome increases the risk of liver fibrosis progression in patients with chronic hepatitis B: a prospective cohort study with paired transient elastography examinations. Aliment Pharmacol Ther. 2014;39:883-93.

28 Wang MM, Wang GS, Shen F, Chen GY, Pan Q, Fan JG. Hepatic steatosis is highly prevalent in hepatitis B patients and negatively associated with virological factors. Dig Dis Sci. 2014;59:2571-9.

29 Joo EJ, Chang Y, Yeom JS, Ryu S. Hepatitis B virus infection and decreased risk of nonalcoholic fatty liver disease: a cohort study. Hepatology. 2017;65:828-35.

30 Zhong GC, Wu YL, Hao FB, Rao XW, Yuan XW, Zhao Y, et al. Current but not past hepatitis $B$ virus infection is associated with a decreased risk of nonalcoholic fatty liver disease in the Chinese population: a case-control study with propensity score analysis. J Viral Hepat. 2018;25:842-52.

31 Wong VW, Wong GL, Chu WC, Chim AM, Ong A, Yeung DK, et al. Hepatitis B virus infection and fatty liver in the general population. J Hepatol. 2012;56:533-40.

32 Xiong J, Zhang H, Wang Y, Wang A, Bian J, Huang $\mathrm{H}$, et al. Hepatitis B virus infection and the risk of nonalcoholic fatty liver disease: a meta-analysis. Oncotarget. 2017;8:107295-302.

33 Machado MV, Oliveira AG, Cortez-Pinto H Hepatic steatosis in hepatitis B virus infected patients: meta-analysis of risk factors and comparison with hepatitis $\mathrm{C}$ infected patients. J Gastroenterol Hepatol. 2011;26:1361-7.

34 Zhang Z, Pan Q, Duan XY, Liu Q, Mo GY, Rao GR, et al. Fatty liver reduces hepatitis B virus replication in a genotype $B$ hepatitis $B$ virus transgenic mice model. J Gastroenterol Hepatol. 2012;27:1858-64.

35 Chu CM, Lin DY, Liaw YF. Clinical and virological characteristics post HBsAg seroclearance in hepatitis B virus carriers with hepatic steatosis versus those without. Dig Dis Sci. 2013;58:275-81.

36 Feldstein AE, Canbay A, Angulo P, Taniai M, Burgart LJ, Lindor KD, et al. Hepatocyte apoptosis and Fas expression are prominent features of human nonalcoholic steatohepatitis. Gastroenterology. 2003;125:437-43.

37 Sherman RE, Anderson SA, Dal Pan GJ, Gray GW, Gross T, Hunter NL, et al. Real-world evidence: what is it and what can it tell us? $\mathrm{N}$ Engl J Med. 2016;375:2293-7.

38 Ray Kim W, Berg T, Asselah T, Flisiak R, Fung $\mathrm{S}$, Gordon SC, et al. Evaluation of APRI and FIB-4 scoring systems for non-invasive assessment of hepatic fibrosis in chronic hepatitis B patients. J Hepatol. 2016;64:773-80. 